skua have been taken a little farther north in lat. $83^{\circ} 7^{\prime} \mathrm{N}$.

After the breeding season there is a general tendency for ptarmigan, which have nested in the higher parts of the interior, to move down towards the coast, but this movement depends to a great extent on the snowfall. In the peak years, however, there is a wellmarked north-to-south migration in vast packs, and a bird ringed in July 1949 on Disko Island was recovered in the following February at Julianehåb, $1,000 \mathrm{~km}$. to the south. At Godhavn in 1949 all the ptarmigan shot there during the winter were males, and when packs from the south appeared in the early spring they too were males, to be followed early in May by packs of females. In these peak years the number of birds which migrate to the south is enormous, and vast numbers are killed for food. Dr. Salomonsen has much of interest to tell of the food and habits of the ptarmigan, and he mentions that in winter the birds roost at night under the lee of a rock in a crevice or in a hole $20 \mathrm{~cm}$. deep dug into the snow by the bird itself.

Of the fourteen different forms of wading birds which occur in Greenland, ten are known to breed, and they include the knot, the eggs of which were such a prize to egg collectors in the early part of the present century. Both the European and American golden plovers visit the country in spring and autumn, but so far none has remained to breed, and most of the birds shot in the autumn are young of the year. The Iceland form of the whimbrel is likewise a spring and autumn visitor, and Dr. Salomonsen considers that both the European golden plover and whimbrel, which reach Greenland in the spring, have been blown out of their course when migrating from the British Isles to Iceland. This, however, can scarcely be the case in the autumn.

The skuas and gulls comprise eleven species and include that rare and beautiful bird, Ross's gull, which has occurred on eighteen occasions in the spring on the west coast of Greenland. This gull nests in eastern Siberia, but Dr. Salomonsen suggests that there may be a colony on some of the Canadian Arctic islands, as some of the birds shot in Greenland were in breeding condition. There is a single record of Ross's gull nesting among a colony of terns near Disko Bay in 1885. Two eggs were laid and the birds shot, but doubt has been cast on the authenticity of the eggs, one of which is now in Copenhagen and the skin of one of the parent birds in the British Museum. Dr. Salomonsen considers this record is correct, and there is reason to think he is right.

N. B. KinnEAR

\section{STATISTICS AND MENTAL TESTS}

Theory of Mental Tests

By Prof. Harold Gulliksen. (Wiley Publications in Psychology.) Pp. xix +486 . (New York: John Wiley and Sons, Inc.; London: Chapman and Hall, Ltd., 1950.) 48s. net.

TF that old friend and inveterate sightseer, the 1 visitor from Mars, were informed that a large, learned and modern book on the theory of mental tests contained not one word about the nature of intelligence, aptitude, intellectual processes or indeed any other attribute of the human mind, he might be surprised. The present reviewer, who does not come from Mars, is not so much surprised as resigned.
These things are signs of the times. After the innumerable and fruitless discussions, arguments and effusions occasioned by the problems of intelligence and aptitude, there has been some reaction towards the firmer ground of statistical methodology. Statisties has always played a large part in mental testing; but one might be inclined to wonder whether the servant is not in a fair way to becoming the master. That is perhaps an exaggeration; it would be fairer to say that Prof. H. Gulliksen has made a special study of this aspect-what may be called the mathematical theory of testing the test. A book on the theory of structures will tell you how to calculate the strength of any given structure, but it will not, except in a few simple cases, tell you how to design a structure for any given job; that is for your ingenuity. There is some justification for taking the same attitude to mental test theory; at any rate, it is clearly the attitude that Prof. Gulliksen does take.

As a text-book on statistics applied to a special field, the book certainly covers a great deal of ground. The student will find that he needs some initial help in grasping the basic ideas of probability distribu. tions, sampling errors, and the jargon of correlations, covariances, etc., and that then the earlier chapters are rather long-winded. The author seems to be straining (commendably) after a simplicity of presenta tion which he never quite attains. A number of "computing diagrams"-families of curves of various commonly-occurring functions--are given, with the suggestion that the student should reproduce them to a large scale. Some of them will undoubtedly be useful, but it seems unlikely that many people will take the trouble to use a chart when they have to add two variances together.

Ono of the basic concepts used by the author is that of parallel tosts. These, though differing in detail, are defined as being statistically indistinguish. able, so that "it does not matter which test you use". Parallel tests should give, in the long run, equal means and variances, and should have equal reliabilities. They should also have approximately equal validities for any given criterion. The validity of a test is its predictive value, as measured by the correlation of the scores with, say, scholastic achievement. It is not immediately obvious why the author adds that parallel tests, in addition to satisfying statistical criteria, should contain items dealing with the same subject-matter and having the same format-in other words, that they "should be parallel as far as psychological judgment is concerned". 'The explana. tion that springs to mind-if one rejects the obvious 'sop to Cerberus' and 'insurance policy' hypotheses -is that the statistical criteria are not adequate. But it is hard to see any fundamental reason why they could not be made so.

Among the topies dealt with, mostly in terms of this concept of parallel tests, are errors of measurement and prediction, effects of test-length, group heterogeneity, "speed" and "power" tests, and problems of standardizing and weighting, etc. Oddly enough, there is no section dealing explicitly with factor analysis, although the procedure is mentioned here and there in various connexions. This is doubt. less no accident, but probably the result of a general veering towards a more empirical and perhaps more fundamental approach. A large number of exercises for students are included, as well as an appendix on elementary algebraic and other formulæ. Taking it as a whole, this is a book for the specialist, in all his metamorphoses from egg to imago. W. E. Hick 